\title{
Microstructural characterization of the ODS Eurofer 97 EU-batch
}

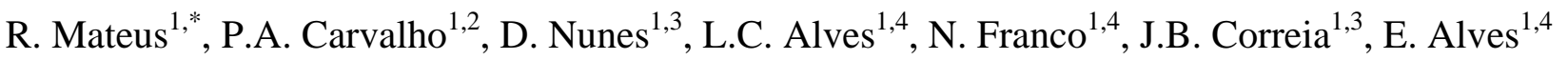 \\ Associação Euratom/IST \\ ${ }^{1}$ Instituto de Plasmas e Fusão Nuclear - Laboratório Associado, Instituto Superior Técnico, \\ Av. Rovisco Pais, 1049-001 Lisboa, Portugal \\ ${ }^{2}$ ICEMS, Departamento de Engenharia de Materiais, Instituto Superior Técnico, \\ Av. Rovisco Pais, 1049-001 Lisboa, Portugal \\ ${ }^{3}$ LNEG, Departamento de Materiais e Tecnologias de Produção, Estrada do Paço do Lumiar, 1649-038 Lisboa, Portugal \\ ${ }^{4}$ ITN, Instituto Tecnológico e Nuclear, Estrada Nacional 10, 2686-953 Sacavém, Portugal
}

\begin{abstract}
Four as-processed forms (Plate 16, Plate 6, Rod 20 and Rod 12.5) of the ODS Eurofer 97 EU-batch produced under different thermomechanical conditions have been investigated by scanning nuclear microprobe, scanning and transmission electron microscopy, energy dispersive X-ray spectroscopy, electron backscattered diffraction, hightemperature X-ray diffraction and microhardness measurements. The materials presented a ferritic microstructure with a homogeneous distribution of $Y$. The thicker plate presented a fine carbide dispersion while the other forms showed carbide morphologies corresponding to pseudo-pearlitic and pseudo-bainitic transformations with wellmatched hardness values. Hot rolling induced crystallographic textures of the $\{101\}<10 \overline{1}>$ type, rotary swaging resulted in a complex texture, and extrusion produced a strong $<101>$ fiber texture. X-ray diffraction experiments at high temperature showed that at a cooling rate of $5{ }^{\circ} \mathrm{C} / \mathrm{min}$ the complete austenite-to-ferrite transformation occurs between 760 and $750^{\circ} \mathrm{C}$ compromising the material quenchability.
\end{abstract}

Keywords: ODS RAFM steel, chemical composition, microstructure

\section{Introduction}

Reduced activation ferritic/martensitic (RAFM) steels as Eurofer 97 have been developed for fusion reactor applications from the conventional $9 \mathrm{Cr}-1 \mathrm{Mo}$ steel modified by replacing high neutron activation elements, such as Mo and Nb, by low neutron activation equivalents, such as $\mathrm{W}, \mathrm{V}$ and Ta $[1,2]$. The materials design has been aimed at enhancing specific properties, namely tensile strength at moderate temperatures as well as swelling and creep resistances [2,3].

In oxide dispersion strengthened (ODS) RAFM steels, the oxide nanoparticles tend to retard grain growth through a boundary pinning effect $[4,5]$, which improves the system thermal stability and allows extending the working temperature [6,7]. Oxide nanoparticle dispersions also increase the resistance to irradiation damage since the particles act as trapping sites for structural defects induced by radiation [4]. In the European Union, ODS RAFM research has been essentially focused on Eurofer 97 reinforced with a low content of ytria [6-9] and 0.3 wt.\% $\mathrm{Y}_{2} \mathrm{O}_{3}$ has been pointed out as reference [2,4]. Nevertheless, in spite of superior strength, thermal stability and irradiation resistance, the impact behaviour and the ductile-to-brittle transition temperature of ODS Eurofer 97 still do not meet the requirements [6,7]. Recent investigation suggests that these shortcomings may be resolved by suitable thermomechanical processing [7].

In this study an ODS Eurofer 97 steel batch produced by PLANSEE (EU-batch) has been investigated in the as-processed industrial conditions. Chemical, structural and morphological characterization of the phases present in the as-received materials was carried out by scanning nuclear microprobe ( $\mu$-PIXE), scanning and transmission electron microscopy (SEM and TEM), energy dispersive X-ray spectroscopy (EDS), electron backscattered diffraction (EBSD), high-temperature X-ray diffraction (HT-XRD) and microhardness measurements.

\section{Experimental procedure}

The EU-batch of ODS Eurofer 97 was produced at PLANSEE in collaboration with FZK Institute of Karlsruhe. Inert-gas-atomized Eurofer 97 steel powder was mechanically alloyed with 0.3 wt. $\% \mathrm{Y}_{2} \mathrm{O}_{3}$ powder under an inert atmosphere by industrial high-energy milling. The consolidation process was performed via Hot Isostatic Pressing (HIP) for $2 \mathrm{~h}$ at $1150{ }^{\circ} \mathrm{C}$ and 100 $\mathrm{MPa}$, followed by deformation at $1150{ }^{\circ} \mathrm{C}$ through: (i) hot rolling, using a route involving cross-rolling along two orthogonal directions to provide homogeneous inplane properties, or (ii) rotary swaging and hot extrusion. Two plates with thicknesses of 16 and $6 \mathrm{~mm}$ (designated, respectively, by Plate 16 and Plate 6) were produced with sequential rolling reductions and two rods with diameters of 20 and $12.5 \mathrm{~mm}$ (designated, respectively, by Rod 20 and Rod 12.5) were produced by rotary swaging, followed by hot extrusion in the latter case. Details of the thermomechanical parameters and procedures are however proprietary and have not been disclosed by PLANSEE. The forms were subsequently sent to IST/ITN for investigation.

Scanning nuclear microprobe investigations were carried out with $2.0 \mathrm{MeV}$ proton beams of $\sim 3 \mathrm{x} 3 \mu \mathrm{m}^{2}$. V, 
$\mathrm{Cr}, \mathrm{Mn}$ and Fe distribution maps were obtained using currents of $100 \mathrm{pA}$ and a 50 $\mathrm{mm}$ Mylar filter. Due to the low concentration of $\mathrm{W}$ and $\mathrm{Y}$ their detection was achieved with a current of $1 \mathrm{nA}$ and a mixed filter composed of $125 \mu \mathrm{m}$ Mylar, $300 \mu \mathrm{m} \mathrm{Al}$ foil and $1 \mathrm{~mm}$ Perspex that preferentially absorbs iron photons. Quantitative analysis of the spectra was performed with the DAN32 code [10].

SEM investigations were performed with a field emission gun JEOL JSM-7001F instrument, equipped for EDS and EBSD analyses. Corresponding data analyses were performed respectively with INCA and CHANNEL 5 Oxford Instruments package codes [11]. Prior to SEM observation the samples were mirror quality polished and etched with Vilella's reagent. Evaluation of grain size and morphology as well as texture determination were carried out by EBSD at 20 $\mathrm{keV}$. Sample preparation for EBSD involved a second polishing step performed with a commercial suspension of alumina $(0.1 \mu \mathrm{m})$. TEM observations have been performed with a Hitachi H8100 instrument operated at $200 \mathrm{kV}$. Samples were thinned to electron transparency by argon ion milling using a Gatan-Duo Mill.

Vickers microhardness data were carried out with a load of $200 \mathrm{~g}$ using a Shimadzu instrument according to the ISO 6507-1 standard.

The quenchability of the EU-batch was investigated by in situ HT-XRD of $11 \times 9 \times 2 \mathrm{~mm}^{3}$ samples using the Plate 6 form under a vacuum pressure of $10^{-4}$ mbar. $\mathrm{Cu}$ $\mathrm{K}_{\alpha, \beta}$ lines were collimated with a Gobël mirror and a divergent slit of $1 \times 10 \mathrm{~mm}^{2}$, and filtered with a $\mathrm{Ge}(111)$ two-crystal monochromator. After full austenitization the samples were cooled at a rate of $5{ }^{\circ} \mathrm{C} / \mathrm{min}$. Temperature measurements were performed with a thermocouple welded to the sample surface and double-checked with a micro-optical pyrometer (PYRO 95). Above $700{ }^{\circ} \mathrm{C}$, the temperature deviations detected with the pyrometer were below 1\%. XRD spectra were collected continuously during cooling using a MBraun ASA 50M PSD detector with an acquisition time of $18 \mathrm{~s}$ in the 40 to $48^{\circ} 2 \theta$ range. The onset and end temperatures of the austenite-toferrite transformation were determined respectively from the $\{111\}_{\gamma}\{110\}_{\alpha}$ intensities.

\section{Results and discussion}

The final strength of ODS materials depends on the homogeneity of the oxide nanoparticle distribution $[6,8,9]$ which can be optimized by a suitable control of the production parameters [2]. Fig. 1 presents typical Xray spectra obtained by nuclear microprobe, where $\mathrm{Fe}$, $\mathrm{Cr}, \mathrm{W}$ and $\mathrm{Y}$ peaks are indicated. $\mu$-PIXE elemental maps showed homogeneous distributions in all the samples within the probe spatial resolution $\left(\sim 3 \mathrm{x} 3 \mu \mathrm{m}^{2}\right)$. The distribution maps obtained for $\mathrm{Y}$ are presented in Fig. 2 (the contrast of each map depends on the individual collected beam charge used and is not a measure of relative concentration). TEM inspection revealed the oxide fine dispersion (Fig. 2(a)). These results point to an enhanced homogeneity in the $\mathrm{Y}$ oxide distribution as compared to other ODS Eurofer 97 batches [9]. The mean composition determined by $\mu$-PIXE lies within the standard concentration range of ODS Eurofer 97 steel (see Table I) [4,12].

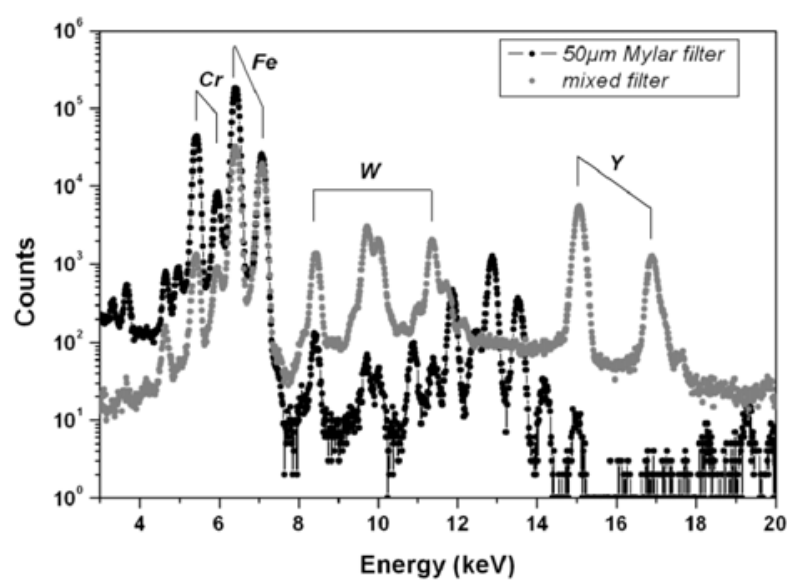

Fig. 1. Typical PIXE spectra of ODS Eurofer 97.

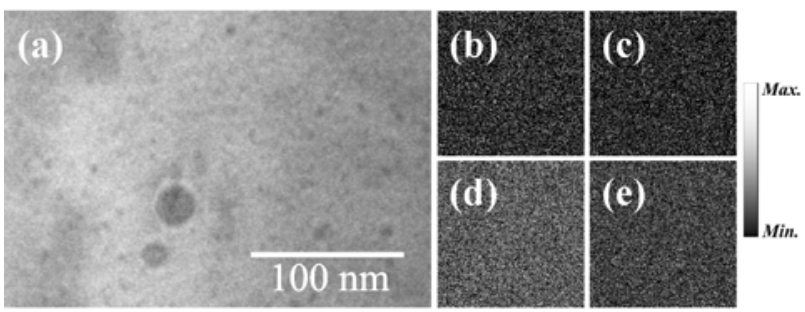

Fig. 2. Bright-field TEM image of a Plate 16 sample exhibiting a nanoparticles dispersion (a); distribution maps obtained from the $\mathrm{Y} \mathrm{K}_{\alpha}$ line with $264 \times 264 \mu \mathrm{m}^{2}$ proton beam scans of: Plate 16 (b), Plate 6 (c), Rod 20 (d), Rod12.5 (e).

Table I. EU-batch composition (wt.\%) obtained by $\mu$-PIXE

\begin{tabular}{lllllll}
\hline Sample & $\mathrm{V}$ & $\mathrm{Cr}$ & $\mathrm{Mn}$ & $\mathrm{W}$ & $\mathrm{Mo}$ & $\mathrm{Y}_{2} \mathrm{O}_{3}$ \\
\hline Plate 16 & 0.178 & 9.30 & 0.65 & 1.12 & 0.0060 & 0.25 \\
Plate 6 & 0.177 & 9.29 & 0.60 & 1.12 & 0.0072 & 0.29 \\
Rod 20 & 0.186 & 9.23 & 0.56 & 1.11 & 0.0089 & 0.27 \\
Rod 12.5 & 0.200 & 9.24 & 0.58 & 1.05 & 0.0062 & 0.24 \\
\hline
\end{tabular}

Plate 16 exhibited globular shaped carbides with sizes below $200 \mathrm{~nm}$ which precipitated continuously throughout the matrix (Figure 3(a)). The other conditions showed an extensive presence of carbide films along grain boundaries (Fig. 3(b)). Klimiankou et al. found similar carbide films in an as-hipped ODS Eurofer 97 [7]. A closer inspection to these microstructures revealed pseudo-pearlitic and pseudo-bainitic morphologies that typically result from the diffusive eutectoid transformations of austenite (see Figs. 3(c) and 3(d)). Local EDS measurements detected higher $\mathrm{Cr}$ and $\mathrm{W}$ concentrations at the precipitates as compared to the matrix composition, indicating the presence of $(\mathrm{Cr}, \mathrm{W}, \mathrm{Fe})$ carbides. Carbide films along grain boundaries are known to increase both hardness and brittleness in steels [13], whereas Cr-rich intergranular precipitates have been associated with neighbouring Cr-depleted zones, known to induce lower corrosion resistance and a decreased in tensile ductility and resilience $[7,13,14]$. 
Since the hot deformation processes were carried out at $1150{ }^{\circ} \mathrm{C}$, i.e., well into the austenite stability domain of the steel [15], it can be assumed that the eutectoid carbide structures, i.e., grain boundary films and pseudobainitic and pseudo-perlitic structures, observed in Plate 6 and Rods 20 and 12.5 were formed during cooling (probably in air) after the thermomechanical treatment. In the case of Plate 16, the complete absence of eutectoid structures evidences a higher cooling rate. However, since the thicker plate should cool at a lower rate, and therefore present coarser eutectoid carbide structures, it can be inferred that Plate 16 was heat treated after rolling (water quenching/tempering) to form a fine carbide dispersion (see Fig. 3 (a)).

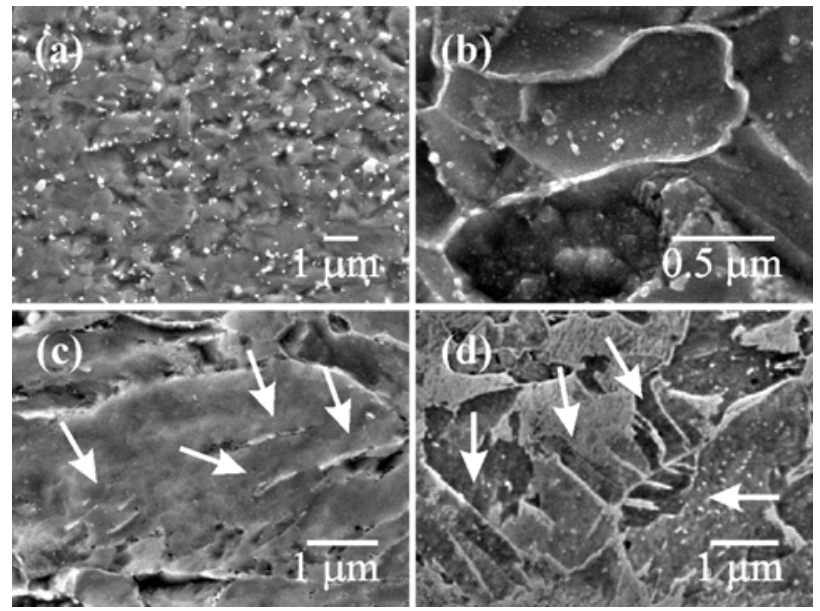

Fig. 3. Carbide morphologies and distribution: globular shape in a continuous dispersion in Plate 16 (a); films along grain boundaries (b), incipient lamellar pearlite-like (c) and bainitelike morphologies (d) observed in the other forms.

EBSD results (Table II and Fig. 4) have been obtained from the rolling plane and transverse crosssection of the plates, and from transverse cross-sections of the rods. Over $95 \%$ of the diffraction patterns have been identified as ferrite. The non-identified material was essentially associated with grain boundary structures and/or precipitates. Table II presents average ferrite grain size. Pole figures obtained from Plates 16 and 6 showed similar preferential crystallographic orientations, $\{101\}<10 \overline{1}>$. Pole figures obtained from the transverse cross-sections of rods revealed a complex texture for the swaged material (Rod 20) and a strong <110> fiber texture for the subsequently extruded material (Rod 12.5) (see Fig. 4). Table II presents also the hardness values obtained from each surface and the results point to a fairly isotropic behaviour. The hardness variations of each form seem strongly associated with carbide morphology/distribution and are in agreement with hardness values obtained for heat-treated EU-batch material (water-quenching/tempering in the case of Plate 16 , and air quenching in the case of the other forms [16].

In order to assess the quenchability of the EU-batch, HT-XRD experiments have been carried out on the asreceived Plate 6 during cooling at a rate of $5^{\circ} \mathrm{C} / \mathrm{min}$ after austenitization at $1050{ }^{\circ} \mathrm{C}$ for $20 \mathrm{~min}$. Contrarily to Eurofer 97, which can be fully austenitized at $980{ }^{\circ} \mathrm{C}$
[15], the present material evidenced traces of ferrite up to $1000{ }^{\circ} \mathrm{C}$. The results shown in Fig. 5(a) demonstrate that upon cooling the complete austenite-to-ferrite transformation occurred swiftly between 760 and $750{ }^{\circ} \mathrm{C}$. The overlapping of the HT-XRD data curve with the CC-TTT diagram (continuous-cooling transformationtemperature-time diagram) of Eurofer 97 [15] (see Fig. 5(b)) show that the EU-batch cannot be fully quenched by air-cooling. The lower quenchability, as compared to Eurofer 97, originates from the significantly lower carbon concentration resulting from losses in the atomization process and poses serious economical constraints on industrial fabrication [6]. Additionally, the higher carbon content required to prevent diffusive precipitation under air-cooling conditions may significantly worsen properties such as impact behaviour and ductile-to-brittle transition temperature. ODS steel with an adequate matrix composition seems therefore required for a suitable assessment of the mechanical behaviour under ITER relevant conditions.

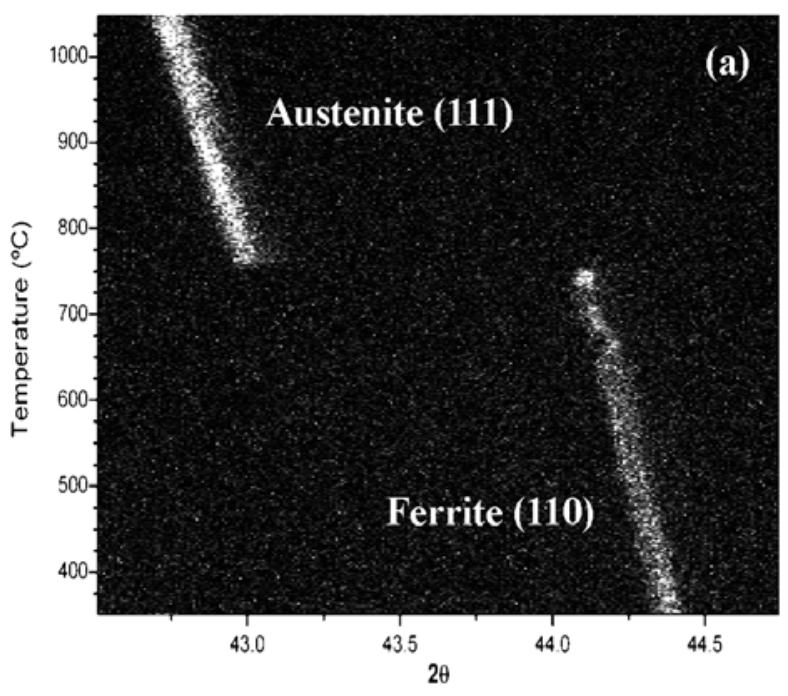

Eu-Batch ODS Eurofer 97

Austenitising temperature: $1050^{\circ} \mathrm{C}$ for $20 \mathrm{~min}$ Grain size: $\sim 1$ um

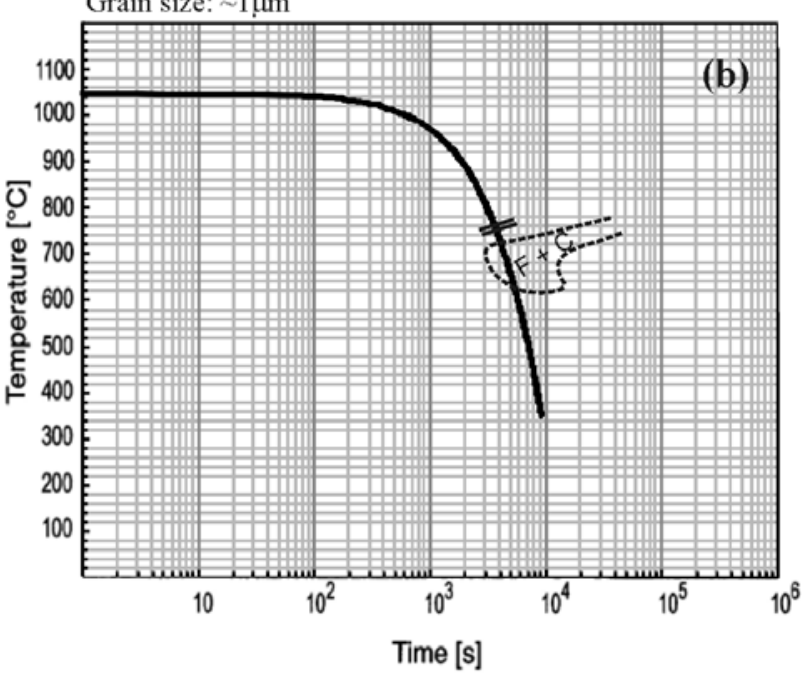

Fig. 5. X-Ray diffraction intensity during cooling (a). Cooling curve and transformation of the EU-batch (solid lines at 760 and $750{ }^{\circ} \mathrm{C}$ ) and the CC-TTT diagram of Eurofer 97 (dashed line) [15] (b). 

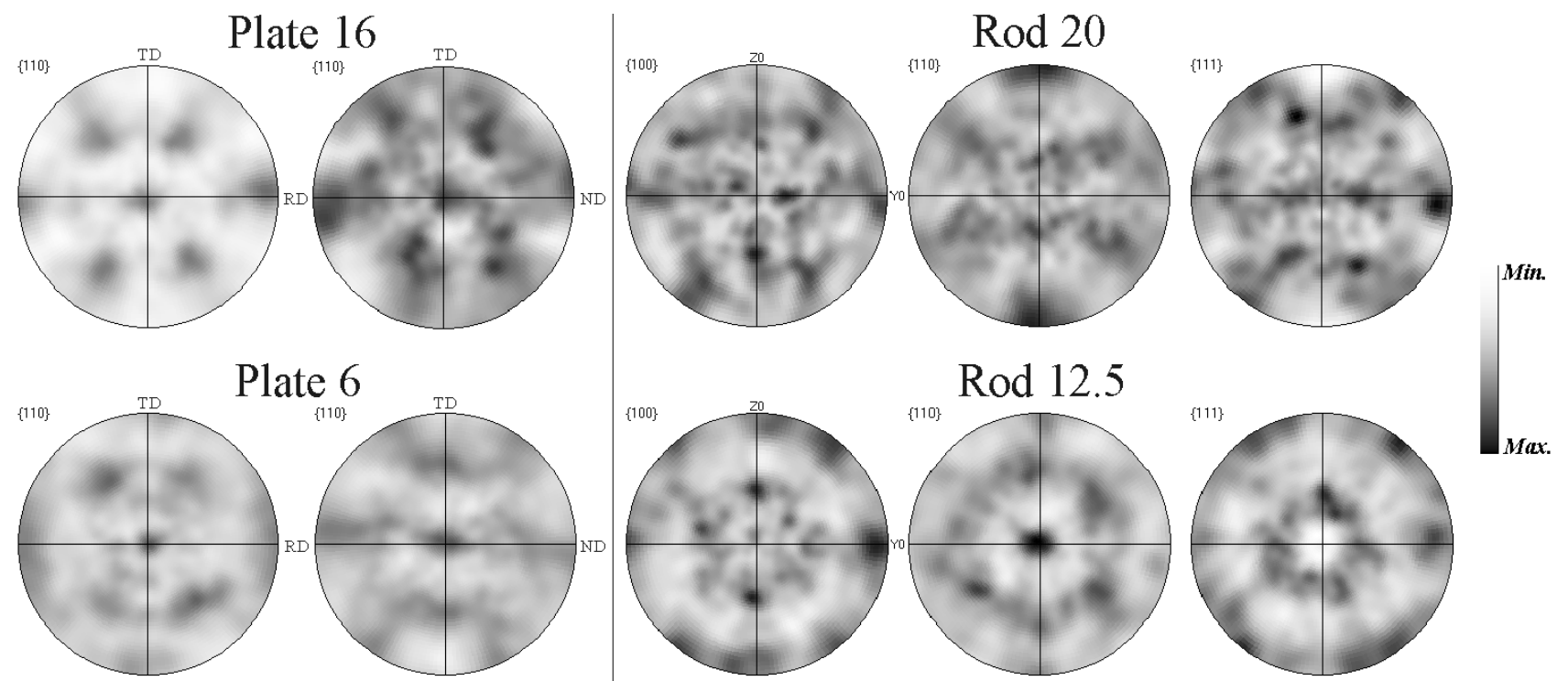

Fig. 4. $\{110\}$ pole diagrams of EBSD scanning maps carried out along rolling planes (column 1) and transverse cross-sections (column 2) of Plate 16 and Plate 6; pole diagrams of EBSD scanning maps carried out from transverse cross-sections of Rod 20 and Rod 12.5 (columns 3 to 5).

Table II. Grain size, crystallographic orientation and hardness

\begin{tabular}{llll}
\hline Sample & $\begin{array}{l}\text { Grain } \\
\text { size, } \\
(\mu \mathrm{m})\end{array}$ & Texture* & $\begin{array}{l}\text { Hardness } \\
(\mathrm{HV} 0.2)\end{array}$ \\
\hline $\begin{array}{l}\text { Plate 16 } \\
\text { (rolling plane) }\end{array}$ & 2.0 & $\mathrm{ND} / /<101>$ & $381.9 \pm 31.5$ \\
$\begin{array}{l}\text { Plate 16 } \\
\text { (transverse section) }\end{array}$ & 1.1 & $\mathrm{RD} / /<10 \overline{1}>$ & $380.8 \pm 31.3$ \\
\hline $\begin{array}{l}\text { Plate 6 } \\
\text { (rolling plane) }\end{array}$ & 1.4 & $\mathrm{ND} / /<101>$ & $507.4 \pm 31.1$ \\
$\begin{array}{l}\text { Plate 6 } \\
\text { (transverse section) }\end{array}$ & 0.8 & $\mathrm{RD} / /<10 \overline{1}>$ & $512.9 \pm 31.4$ \\
\hline $\begin{array}{l}\text { Rod 20 } \\
\text { (longitudinal plane) }\end{array}$ & 1.0 & - & $514.8 \pm 31.1$ \\
$\begin{array}{l}\text { Rod 20 } \\
\text { (transverse section) }\end{array}$ & 1.1 & $\mathrm{Complex}$ & $520.8 \pm 31.1$ \\
\hline $\begin{array}{l}\text { Rod 12.5 } \\
\text { (longitudinal plane) }\end{array}$ & 0.9 & - & $521.2 \pm 31.4$ \\
$\begin{array}{l}\text { Rod 12.5 } \\
\text { (transverse section) }\end{array}$ & 0.9 & $\mathrm{FD} / /<101>$ & $514.8 \pm 31.0$ \\
\hline
\end{tabular}

* ND stands for normal direction, RD for rolling direction and FD for fiber direction.

\section{Conclusions}

EU-batch presented homogeneous distribution of $\mathrm{Y}$ in a ferritic microstructure decorated with carbide precipitates. A fine carbide dispersion was found in the thicker plate whereas the other forms presented carbide morphologies related to pseudo-pearlitic and pseudobainitic diffusive transformations with well-matched hardness values. Rolled plates showed crystallographic textures of the $\{101\}<10 \overline{1}>$ type, rotary swaging resulted in a complex texture, whereas extrusion produced a strong $<101>$ fiber texture. X-ray diffraction data at high temperature revealed that at a cooling rate of $5{ }^{\circ} \mathrm{C} / \mathrm{min}$ the complete diffusive transformation of austenite occurs between 760 and $750{ }^{\circ} \mathrm{C}$ hindering air quenching.

\section{Acknowledgments}

This work was performed within the Contract of Association EURATOM / IST. Financial support was also received from FCT (Fundação para a Ciência e Tecnologia) in the frame of the Associated Laboratory Contract.

\section{References}

[1] J. Waering, A.-A.F. Tavassoli, Transactions of the $13^{\text {th }}$ International Conference in Structural Mechanics in Reactor Technology, Porto Alegre, Brazil, Univ. Fed. Rio Grande do Sul, 13-18 August 1995, Division E, p.563.

[2] N. Baluc et al., Nucl. Fusion 47 (2007) S696.

[3] N. Baluc et al., J. Nucl. Mater. 367-370, (2007) 33.

[4] M.S. El-Genk, J.M. Tournier, J. Nucl. Mater. 340 (2005) 93.

[5] T. Hayashi, P.M. Sarosi, J.H. Schneibel, M.J. Mills, Acta Mater. 56 (2008) 1407.

[6] R. Lindau, A. Möslang, M. Schirra, P. Schlossmacher, M. Klimenkov, J. Nucl. Mater. 307-311 (2002) 769.

[7] M. Klimiankou, R. Lindau, A. Möslang, J. Nucl. Mater. 367-370 (2007) 173.

[8] L.C. Alves, E. Alves, A. Paúl, M.R. da Silva, J.A. Odriozola, Nucl. Instr. and Meth. B 249 (2006) 493.

[9] A. Paúl e tal., Fusion Eng. Des. 75-79 (2005) 1061.

[10] G.W. Grime, Nucl. Instr. and Meth. B 109-110 (1996) 170.

[11] www.oxford-instruments.com

[12] A.-A.F. Tavassoli et al., J. Nucl. Mater. 329-333 (2004) 257.

[13] T.R. Allen et al., J. Nucl. Mater. 351 (2006) 174.

[14] A.Pardo e tal., Acta Mater. 55 (2007) 223.

[15] R. Lindau, A. Möslang, M. Schirra, Fusion Eng. Des. 5859 (2001) 781.

[16] R. Lindau, personal communication. 